
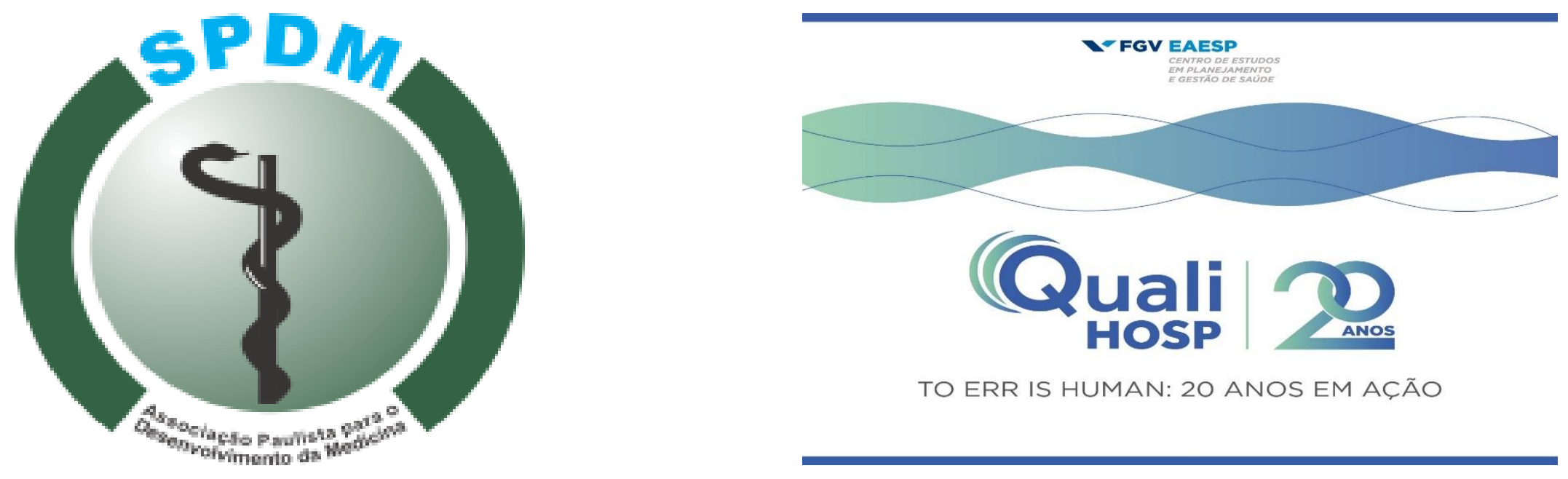

TO ERR IS HUMAN: 20 ANOS EM AÇÃO

\title{
IMPLANTAÇÃO DE GESTÃO DA FILA CIRÚRGICA COMO ESTRATÉGIA DE OTIMIZAÇÃO DAS CIRURGIAS ELETIVAS: UM RELATO DE EXPERIÊNCIA.
}




\section{IMPLANTAÇÃO DE GESTÃO DA FILA CIRÚRGICA COMO ESTRATÉGIA DE OTIMIZAÇÃO DAS CIRURGIAS ELETIVAS: UM RELATO DE EXPERIÊNCIA.}

Introdução: Um sistema de gestão para a excelência do desempenho precisa ter seu foco na organização, na satisfação dos nossos clientes-alvo e cumprimento de metas do contrato de gestão. Quando assumimos a gestão de um hospital público, a quantidade de metas estabelecidas em contrato relacionada a demanda cirúrgica estava reprimida.

Objetivo: Garantir alinhamento do fluxo cirúrgico eletivo com foco no gerenciamento da fila para aumento nos números de cirurgias e diminuição na taxa de suspensão cirúrgica.

Método: Trata-se de um relato de experiência de implantação do modelo de gestão de fila cirúrgica e intervenção da demanda cirúrgica. Iniciamos nossa intervenção em outubro de 2017, com uma adequação fluxo cirúrgico eletivo. 


\section{IMPLANTAÇÃO DE GESTÃO DA FILA CIRÚRGICA COMO ESTRATÉGIA DE OTIMIZAÇÃO DAS CIRURGIAS ELETIVAS: UM RELATO DE EXPERIÊNCIA.}

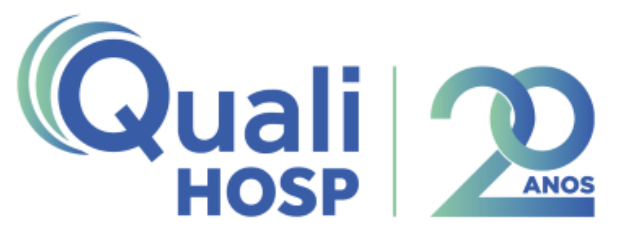

\section{Ações:}

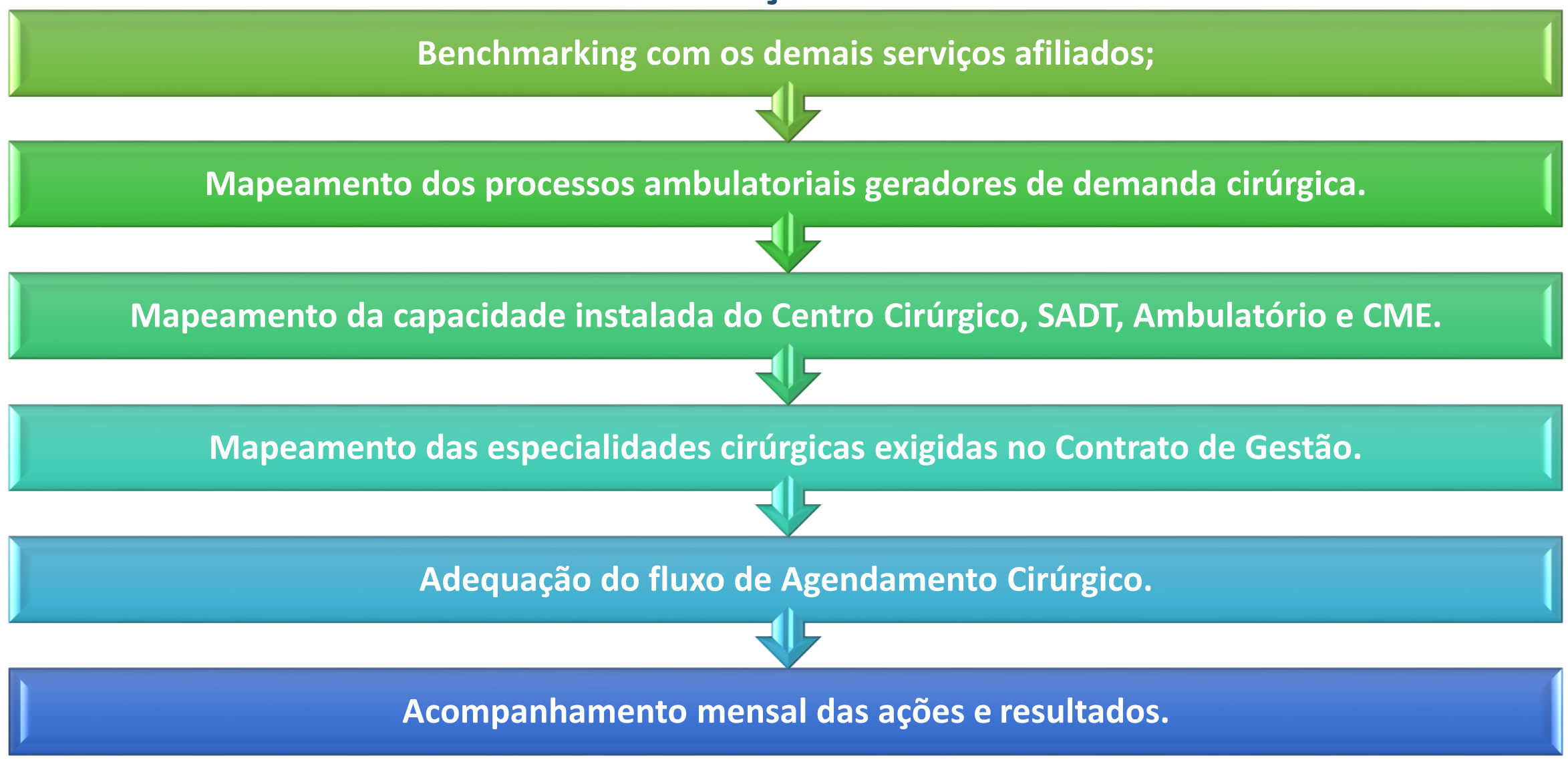




\section{IMPLANTAÇÃO DE GESTÃO DA FILA CIRÚRGICA COMO}

ESTRATÉGIA DE OTIMIZAÇÃO DAS CIRURGIAS ELETIVAS: UM RELATO DE EXPERIÊNCIA.

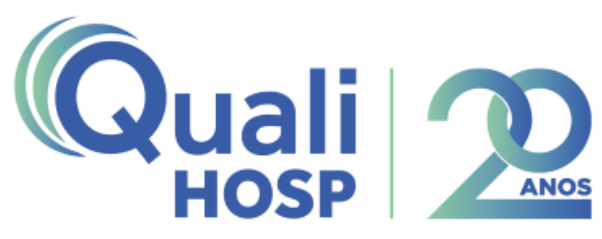

\section{Resultados}

Total de Cirurgias Realizadas - Jul/17 a Jun18 - HMB

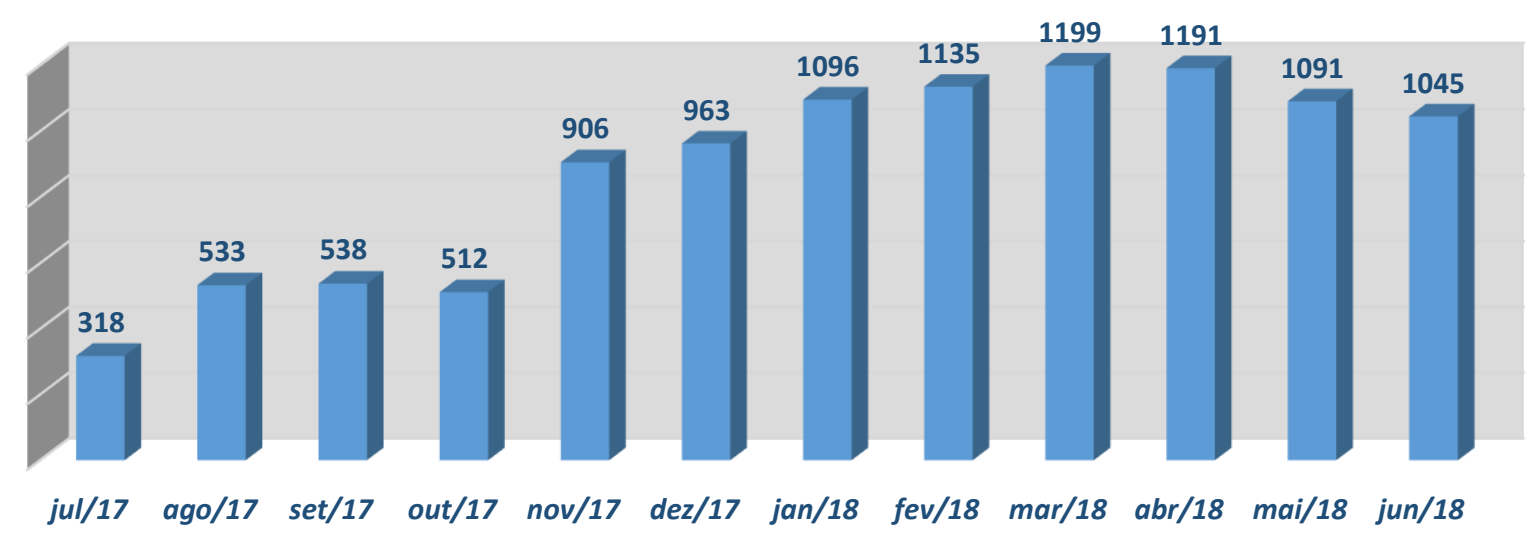

Taxa de Suspensão Cirúrgica - Jul/17 a Jul/18 - HMB Intervenção

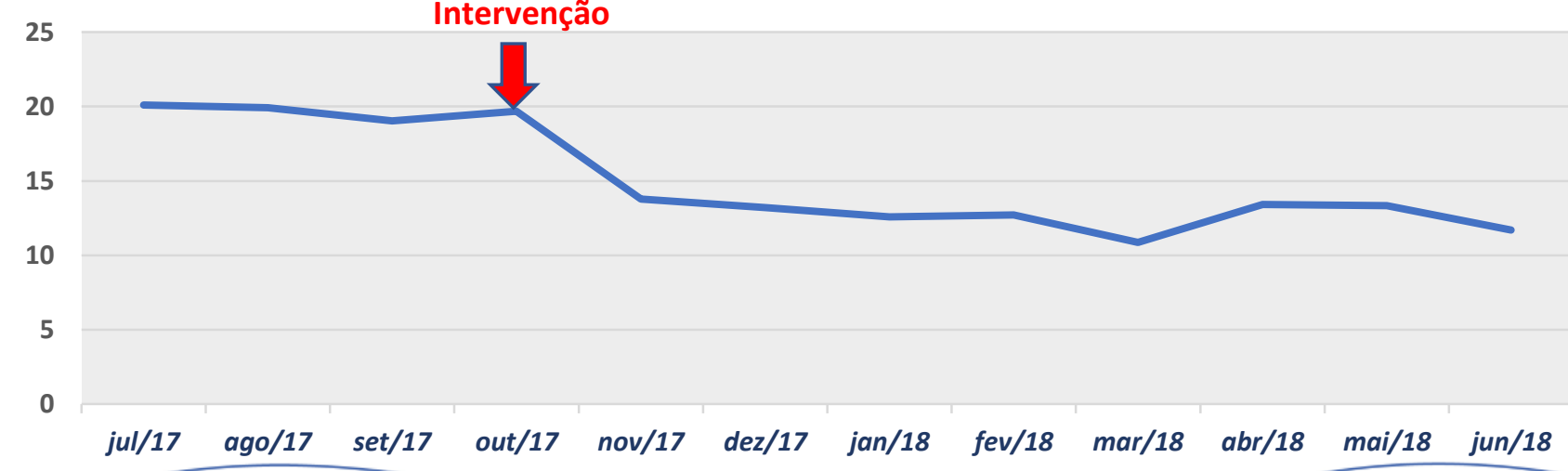


Com gerenciamento diário e metas estabelecidas, conseguimos:

$\checkmark$ Aumentar procedimentos cirúrgicos eletivos em 100\%;

$\checkmark$ Otimizar a confirmação da presença do usuário à cirurgia eletiva por telefone 48-72 horas antes do procedimento cirúrgico;

$\checkmark$ Implantar a reunião multiprofissional para previsão e provisão dos materiais necessários para cirurgia com 48 horas de antecedência (Bate Mapa);

$\checkmark$ Implantar a reconciliação medicamentosa dos pacientes com doenças crônicas, classificação de risco cirúrgico e Critérios de elegibilidade para UTI.

A taxa de suspensão por motivo paciente caiu de $20 \%$ para $12 \%$ num período de 05 meses e zerou os cancelamentos cirúrgicos por motivo material e equipamento.

Conclusão: A intervenção no processo de gerenciamento da cirurgia eletiva trouxe bons resultados, quando realizado com foco nas metas. 


\section{IMPLANTAÇÃO DE GESTÃO DA FILA CIRÚRGICA COMO ESTRATÉGIA DE OTIMIZAÇÃO DAS CIRURGIAS ELETIVAS: UM RELATO DE EXPERIÊNCIA.}

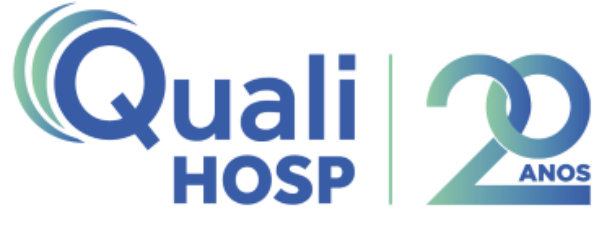

\section{Referência:}

1 Suspensão de cirurgias em um hospital universitário. Carvalho TA, Sobral CB, Marinho PM. Et al. Rev. SOBECC, São Paulo. OUT./DEZ. 2016; 21(4): 186-191.

2 Reestruturação do fluxo de internação para cirurgias eletivas por meio da gestão de processos em um hospital público. Silva, GK, Novaretti MCZ. https://singep.org.br/4singep/resultado/186.pdf

\section{Autores:}

Shirley dos Santos Kimura Kuratomi.

Ellen Zamberlan Milan.

Leila Maria Albertini Reis.

Mirela Baptista Montini.

Cristiane aparecida Betta. 
IMPLANTAÇÃO DE GESTÃO DA FILA CIRÚRGICA COMO ESTRATÉGIA DE OTIMIZAÇÃO DAS CIRURGIAS ELETIVAS: UM RELATO DE EXPERIÊNCIA.

\section{.."O sucesso não vem do quanto você trabalha e sim da eficiência de sua equipe"}

\section{OBRIGADA!}

